\title{
A emergência de um Novo Negro nas páginas do Chicago Defender (1915-1919)
}

\begin{abstract}
Flavio Thales Ribeiro Francisco ${ }^{1}$
Resumo

O objetivo deste artigo é o de demonstrar como a noção de Novo Negro emergiu nas páginas do jornal afro-americano Chicago Defender durante a Grande Imigração. Entre 1915 e 1920, esse periódico se engajou em uma campanha para estimular a imigração de trabalhadores negros para o norte dos Estados Unidos. O Chicago Defender, além de defender o direito dos negros, difundiu imagens e representações positivas de cidades como Chicago, Nova Iorque e Detroit como espaços livres do racismo. Por um lado, o jornal publicou notícias e artigos revelando as atrocidades da violência racial no sul do país, por outro, procurou demonstrar como as cidades do norte ofereciam oportunidades de trabalho sem práticas discriminatórias. Nesse período, Chicago e Nova Iorque atraíram muitos migrantes negros, os jornalistas do Chicago Defender afirmavam que essas cidades eram uma espécie de "terra prometida" onde a população negra poderia ser incluída na modernidade norte-americana. Através de anúncios e artigos, o periódico negro retratou imagens de mulheres e homens negros modernos, um novo cidadão negro completamente incorporado ao capitalismo norteamericano, representando um negro urbano respeitável em oposição aos um agrário e degrado no Sul do país.
\end{abstract}

Palavras chaves: Afro-americanos; novo negro; racism; Chicago Defender

\section{Abstract}

The aim of this article is to demonstrate how the notion of New Negro emerged on the pages of Chicago Defender newspaper during the Great Migration. Between 1915 and 1920, this periodical engaged in a campaign in favor of migration of southern black workers to the northern states. The Chicago Defender, besides advocating the rights of African-Americans, diffused positive images and representations of big cities like Chicago, New York, and Detroit as racism free spaces. On one hand, this black newspaper ran several headlines and articles revealing the atrocities of the racial violence in the American South. On the other hand, it attempted to picture the northern cities as places where black workers cold compete for jobs in a labor market free from racist practices. At this time, Chicago and New York attracted many black migrants, the journalists of Chicago Defender claimed that these cities were the promised land where the African-Americans would be included into American modernity. Through advertisings and articles, the black newspaper depicted the image of the modern black men and women, a new black citizen incorporated into American capitalism, representing the urban respectable black people in opposition to the degraded agrarian people of the poor American South.

Keywords: African-Americans; New Negro; racism; Chicago Defender

Pretendemos aqui fazer uma breve discussão do modo como o jornal afro-americano Chicago Defender difundiu a ideia de metrópoles negras entre as populações negras das zonas rurais e de pequenas cidades dos estados do sul dos Estados Unidos, gestando a ideia de "novo negro". A partir de 1915 uma grande quantidade de trabalhadores, juntos com suas famílias, optou por deixar suas cidades atrás do sonho de condições melhores nas cidades no norte do país, consideradas como livres dos códigos rígidos da segregação racial no sul. Espaços urbanos como o de Chicago, Nova Iorque e Detroit foram representados como as "Mecas" para a ascensão social das populações negras, atraídas pelas supostas ofertas no mercado de trabalho, melhor qualidade nas instituições educacionais e inúmeras opções de lazer. Entre os vários motivos que estimularam o deslocamento de milhares de migrantes negros estava o sonho de participar da uma modernidade negra retratada pelo Chicago Defender, que no ápice do processo migratório, criou uma campanha para que os seus leitores do sul deixassem suas cidades.

1 Doutorando do Programa de Pós-Graduação de História Social da Universidade de São Paulo. E-mail: ffrancisco@usp.br, 
Assim como o ativismo negro de outros países, como o Brasil e Cuba, os afro-americanos nas primeiras décadas do século XX construíram e difundiram imagens de um negro moderno como uma estratégia para combater o imaginário racista. As lideranças negras de São Paulo e Havana, por exemplo, consideraram esse período como um momento de transição no qual a população negra deixava a condição de escravidão para se integrar a uma ordem capitalista, elaborando narrativas de uma redenção negra. ${ }^{2}$ Essa redenção propagada pelos líderes negros cubanos e brasileiros não tinha como ponto de reflexão somente o lugar do negro na economia, havia também uma referência estética orientada por valores que deveriam conduzir a "elevação moral" dos negros. Esses grupos formavam uma "elite" negra assimilada que problematizava a presença de expressões culturais de origens africanas, consideradas como barreiras para o progresso dos negros nos dois países.

O jornal Chicago Defender, ao divulgar imagens de uma modernidade negra em cidades como Chicago e Nova Iorque, criou um discurso de redenção do negro, em que os elementos da cultura popular dos migrantes, entre elas gêneros musicais como o jazz, também eram considerados como um problema para o refinamento moral e cultural, tão necessário para o progresso dos afroamericanos. Essa leitura das lideranças negras no pós-abolição foi uma solução em um período em que ainda se gestava uma crítica teórica ao Ocidente, como no pensamento pan-africanista de Williams DuBois e Marcus Garvey, dentre outros. Portanto, o que acompanharemos a seguir será a atuação de um periódico que não oferecia uma proposta radical emancipadora em relação ordem social, ao invés disso apresentava uma estratégia combativa de confronto ao racismo norteamericano através da representação de um "novo negro" ajustado ao capitalismo norte-americano das primeiras décadas do século XX.

\section{Nasce o Chicago Defender}

O jornal Chicago Defender publicou a sua primeira edição em maio de 1905. Robert Abbott, o seu idealizador, havia deixado Savannah, a sua cidade natal no estado sulista da Geórgia, em busca de oportunidades profissionais na área do direito no norte do país, supostamente aberto à ascensão social de negros neste período de acirramento da segregação racial. Contudo, o sonho de prosperar como advogado foi frustrado justamente pelo preconceito em relação à cor de sua pele na cidade de Indianápolis. Em Chicago, Abbott decidiu investir seus escassos recursos no campo do

2 Ver GURIDY, Frank Andre. Forging diáspora: Afro-Cubans and African-Americans: in a world of empire and Jim Crow. Chapel Hill: University of North Carolina Press, 2010; DE LA FUENTE, Alejandro. A Nation for all: race, inequality, and politics in Twentieth Century Cuba. Chapel Hill: The University of Carolina Press, 2001; BUTLER, Kim D. Freedoms given, freedoms won: Afro-Brazilian in post- abolition, São Paulo and Salvador. New Brunswick: Rutgers University Press, 1998. 
jornalismo, uma vez que possuía conhecimentos neste ofício, aprendidos com o padrasto durante a juventude. Desta maneira, o periódico começou com estrutura precária, editado em um pequeno quarto alugado em uma casa de família. Circulou pela primeira vez com tiragem de 300 exemplares, trazendo apenas quatro páginas.

Os primeiros anos não indicavam o futuro sucesso do Chicago Defender, as receitas eram baixas e o número de leitores restrito. A virada viria somente a partir de 1908, após ter divulgado a ligação de autoridades políticas da cidade com prostíbulos de bairros negros, caso que atiçou a curiosidade dos leitores ${ }^{3}$. Em 1912, o Chicago Defender passou a contar com recursos financeiros estáveis, se popularizando como o jornal que retratava as mazelas e os vícios que assolavam a população negra da cidade.

3 DESANTIS, Alan Douglas. Selling the American Dream: The Chicago Defender and Great Migration of 19151919. Tese de Doutorado, Universidade de Indiana, 1993, p. 96 (mimeogr.) 


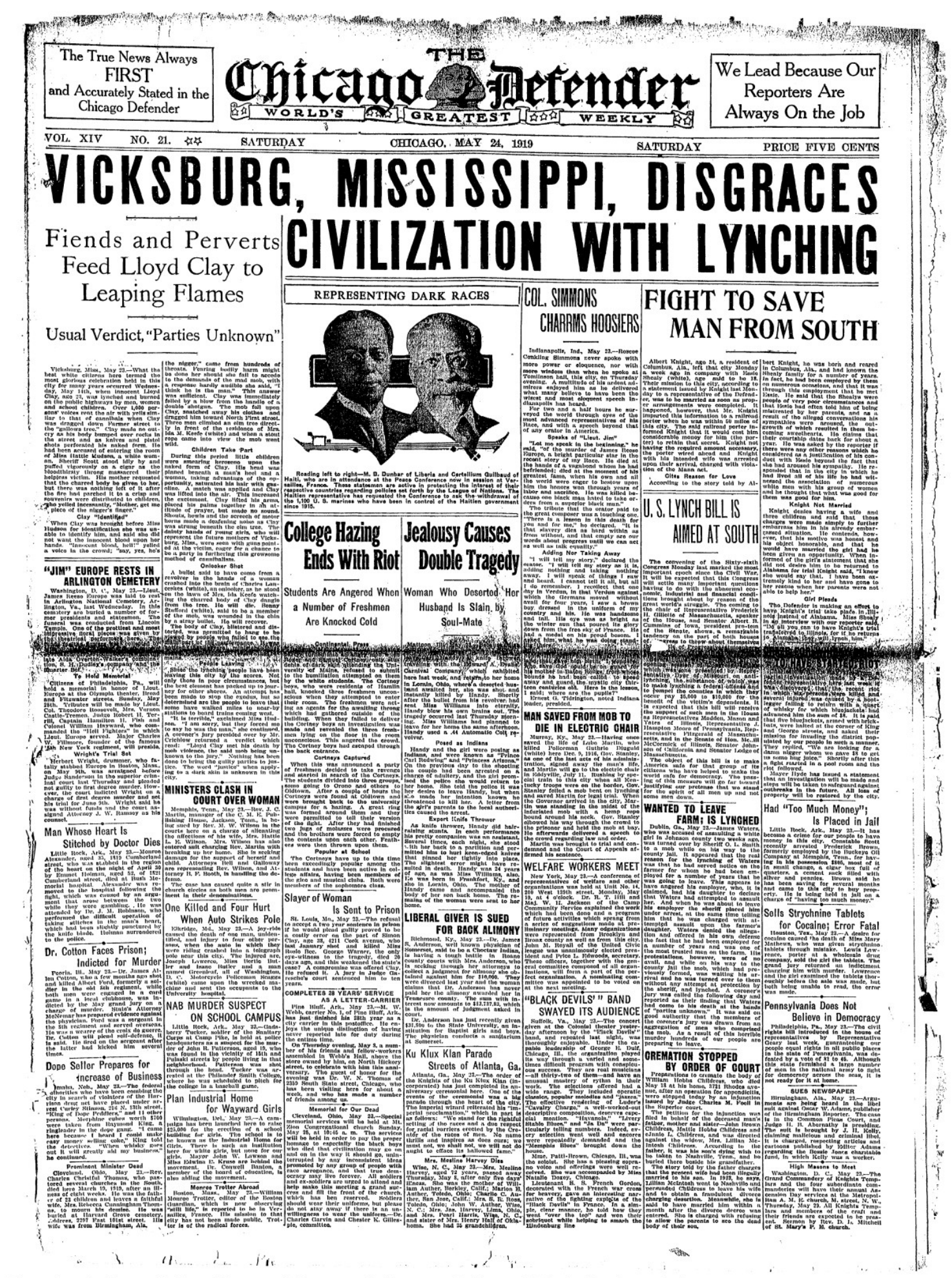

Reproduced with permission of the copyright owner. Further reproduction prohibited without permission.

Figura 0: Manchete sobre linchamento no estado do Mississippi. Chicago Defender de 24 de maio de 1919.

Entretanto, a perspectiva do jornalista não se restringiu à cobertura da miséria, Abbott se posicionou contra as desigualdades sociais que pesavam sobre os negros, sobretudo na área da 
educação ${ }^{4}$. Sendo assim, Abbott foi construindo uma imagem de importante liderança negra na cidade de Chicago, o que tornou seu jornal atraente a uma série de colaboradores que se interessaram pela linha editorial que tratava de maneira combativa as questões raciais.

Entre eles, John Hockley Smiley foi o que deu a maior contribuição para o Chicago Defender. Smiley ocupou a posição de redator entre 1910 e 1915, e transformou o periódico de Robert Abbott em um jornal de grande circulação entre a população afro-americana, chegando a ser distribuído nacionalmente. Vale ressaltar que o fato deste ter sido um jornal setorizado, direcionado ao público negro, não restringia necessariamente o acesso de brancos ao periódico. Entre as estratégias de John Smiley para atrair leitores estava a de renovação do layout do Chicago Defender, aproximando-o do modelo dos grandes jornais de Chicago. O editor acentuou o vermelho das manchetes e destacou notícias sobre a violência no sul dos Estados Unidos na primeira página. O jornal também foi dividido em seções (política, notícias do estado de Illinois, teatro, cinema, esportes), passando a ser editado em 12 páginas.

Outra figura de grande importância na história do Chicago Defender foi Phil Jones, responsável pela distribuição do jornal em escala nacional. Ele circulou por inúmeras cidades norteamericanas, principalmente nos estados do sul, mobilizando uma rede de distribuidores que alavancariam as vendas do periódico 5 . O Chicago Defender continuou a ser publicado semanalmente e a sua tiragem alcançou 250 mil exemplares, algo espetacular para um jornal negro daquele período ${ }^{6}$.

Mesmo operando de maneira profissional e gerando lucro, o periódico afro-americano continuou a ter o seu conteúdo determinado por Robert Abbott, que, por volta da década de 1920, passou a fazer parte de um seleto grupo de prósperos empreendedores negros da cidade de Chicago $^{7}$. Enquanto personificação do Chicago Defender, Abbott se destacou, sobretudo, na campanha em prol da migração da população negra dos estados do sul para as grandes cidades do norte do país. Diante do processo de segregação racial e da onda de linchamentos nas cidades sulistas, o periódico se empenhou em fazer a propaganda positiva de cidades como Detroit, Nova Iorque, Filadélfia e principalmente Chicago; apresentando estas cidades como espaços livres do

4 ELLIS, Charlesetta Maria. Robert S. Abbott's response for education for African-Americans via the Chicago Defender, 1909-1940. Tese de Doutorado, Universidade Loyola de Chicago, 1994. (mimeogr.)

5 DESANTIS, Alan Douglas. op. cit., p. 106.

6 Sobre a imprensa afro-americana em geral ver PRIDE, Armistead S. \& WILSON II, Clint C. A history of the black press. Washington, D.C.: Howard University Press, 1997.

7 Ver BALDWIN, Davarian L. Chicago's Negroes: modernity, Great Migration and Black urban life. Chapel Hill: University of North Carolina Press, 2007. 
ódio racial e sem restrições sociais à ascensão de negros, como veremos mais adiante.

A ascensão nacional do Chicago Defender acompanhou o nascimento e a articulação das primeiras organizações do movimento negro norte-americano como a NAACP - National Association for Advancement for Colored People - (1909) e a UNIA - Universal Negro Improvement Association (1914). Robert Abbott fazia parte de uma geração de ativistas negros como o intelectual de Harvard, William $\mathrm{Du} \mathrm{Bois}^{8}$, que nesse período defendia uma proposta integracionista para os negros, e o "nacionalista negro" ${ }^{9}$ radical Marcus Garvey, que propunha o retorno para a África. Esses homens estavam dentre as maiores lideranças do ativismo afroamericano daquele período, desafiando através de diferentes estratégias os racistas que fomentavam ações violentas em nome de uma supremacia branca na primeira metade do século XX. Abbott, ao seu modo, utilizou o jornal Chicago Defender para lutar pelo mesmo fim. ${ }^{10}$

\section{Abolição e frustração}

Antes que possamos tratar da circulação de representações positivas das "metrópoles negras", é necessário compreendermos a situação das populações negras que habitavam os estados do sul dos Estados Unidos. A Grande Migração somente se torna um evento histórico inteligível se levarmos em consideração que os trabalhadores que optaram pelo deslocamento sofreram com o legado da escravidão norte-americana. A população negra se concentrava majoritariamente no sul dos Estados Unidos, onde o sistema escravista havia se configurado a partir do século XVII e abolido somente em 1863 - os estados do norte concluíram o processo de abolição em 1804. Portanto o fim da escravidão teve um profundo impacto sobre as sociedades sulistas, que deveriam administrar a integração de cerca de quatro milhões de ex-escravos.

A escravidão nos Estados Unidos, diferentemente do Brasil, foi influenciada profundamente por uma guerra civil que opôs estados do norte e parte dos estados do sul do país. À medida que as tropas dos norte do país avançavam sobre as sulistas, os escravos deixavam as

8 DU BOIS, William E. B. As almas da gente negra. Rio de Janeiro: Lacerda Editores, 1999.

9 O nacionalismo negro norte-americano faz referência ao separatismo em relação aos brancos do país.

10 Na década de 1920, o termo New Negro foi atribuído a essa geração de ativistas que se opunha de maneira contundente ao racismo e à segregação racial. Sobre New Negro Movement ver JORDAN, William G. Black newspapers and America's war for democracy, 1914-1920. Chapel Hill: The University of North Carolina Press, 2001; GATES JR, Henry Louis. "The trope of a new negro and the Reconstruction of the image of the Black, Representations” (Special Issue: America Reconstructed, 1840-1940), 24, Fall 1998, pp. 129-155. 
fazendas, compreendendo que a presença dos soldados representava o desmonte do sistema escravocrata. Assim que o conflito chegou ao fim, em 1865, com a presença do norte a partir da sua força militar, os primeiros passos foram dados para a transformação de escravos em cidadãos norteamericanos.

Durante a Reconstrução (1865-1877), em um período de restauração da União após a Guerra Civil, foram criadas políticas para integrar da população negra. O Partido Republicano, influenciado por uma ala radical que procurava afirmar o valor da mobilidade social, se empenhou em oferecer aos libertos os recursos necessários para participarem de maneira efetiva da vida econômica no país. O Departamento dos Libertos teve grande importância ao oferecer assistência aos ex-escravos, distribuindo roupas, comidas e, posteriormente, criando uma estrutura suficiente para que os libertos fossem educados como cidadãos livres, aprendendo a poupar e investir o dinheiro $^{11}$. Embora operando com recursos limitados, o departamento conseguiu atrair uma rede de assistência privada que teve como uma das principais consequências a emergência das instituições de ensino básico e superior para a população negra. Foi nesse período que nasceram proeminentes universidades negras como a Fisk (1866) e a Howard (1867), responsáveis pela formação de uma primeira inteligência afro-americana após a escravidão.

No entanto, os avanços sociais e econômicos da população negra foram interrompidos por uma onda conservadora liderada por muitos políticos do Partido Democrata, preocupados em manter uma hierarquia racial baseada na noção de uma superioridade branca. Os republicanos radicais, por outro lado, perderam espaço no próprio partido, enfraquecendo a base política que sustentava as mudanças sociais em curso. A crise da economia norte-americana também teve impacto negativo, limitando os recursos do Departamento dos Libertos. Em 1877, com a retirada das tropas da União dos estados do sul, o último golpe foi dado, extirpando as políticas voltadas para a população negra.

Os conflitos, já presentes no período da Reconstrução, se manifestaram em escalas ainda maiores, causando retrocesso educacional e político, assim como em esferas sociais. A participação de negros nas eleições foi proibida em estados onde se havia formado uma classe política afroamericana ativa. Grupos compostos por multidões de racistas, expressando o sentimento de ódio, expulsaram fazendeiros bem sucedidos de suas terras, com o intuído de eliminar vestígios de

11 FONER, Eric. Reconstructon: America's unfinished revolution (1863-1877). New York: Harper \& Row, 1988, pp. 68-71. 
progresso da população negra no Sul. Nesse período que antecede o boom econômico dos tempos da Primeira Guerra Mundial, migrantes negros se deslocaram para outras regiões em busca de oportunidades e liberdade inexistentes em áreas segregadas.

O sul do país, então, se tornou palco de demonstrações violentas de racismo. O esforço para manter privilégios através da supremacia racial se revelou na segregação de espaços públicos como ônibus, banheiros, restaurantes e também numa forma mais severa através de estupros e linchamentos. A hierarquia racial da escravidão deu lugar a uma nova ordem social orientada por uma cultura com códigos raciais que determinavam os limites entre brancos e negros, sempre atravessados pelas relações de poder ${ }^{12}$. Ultrapassar a fronteira racial significava desafiar uma ordem marcada por desigualdades sociais e econômicas.

O uso desmedido da brutalidade para manter o status quo gerou uma paranoia racial que vitimou muitos negros nos estados sulistas. Boatos sobre supostas ameaças de negros à população branca foram muitas vezes suficientes para a formação de turbas que devastavam as áreas habitadas pela população negra. O flerte entre homens negros e mulheres brancas, na maioria das vezes alegado sem provas, se transformava em boatos de estupro, pelos quais supostos criminosos eram condenados pelos "tribunais populares" ao enforcamento. A cultura arraigada da violência racial se perpetuou em forma de enforcamentos públicos, assistidos por uma grande quantidade de pessoas, incluindo crianças, o que transformava o atos violentos em grandes eventos.

Neste contexto, as zonas rurais dos estados sulistas tornaram-se ambientes completamente hostis para os afro-americanos. A violência se combinava a outros fatores que faziam da permanência nestas regiões insustentável. Para além da violência de cunho racial, havia uma economia destroçada que ainda se recuperava da Guerra Civil e do desmonte do sistema escravista. O algodão, um dos gêneros mais lucrativos do período da escravidão, perdeu um enorme valor no mercado. Além disso, muitas colheitas foram perdidas com o problema de pragas e desastres naturais $^{13}$. A possibilidade de trabalho na indústria, que permitia a fuga dos trabalhadores das condições precárias do campo, estava restrita aos brancos nessa região do país.

A partir desse quadro crítico, é possível compreender as motivações dos afro-americanos que decidiram migrar para realizar o sonho de prosperidade e liberdade no norte do país. É

12 Ver RITTERHOUSE, Jennifer. Growing up Jim Crow: how black and white southern children learned race. Chapel Hill: The University of South Carolina Press, 2006.

13 GROSSMAN, James R. Land of Hope: Chicago, Black Southerners, and the Great Migration. University of Chicago Press, 1989, p. 15. 
importante, porém, atentarmos para o fato de que o deslocamento da população negra não ocorreu diretamente em direção às metrópoles que se formavam no norte do país. O primeiro fluxo de migrantes, em meados da década de 1860, foi limitada ao próprio sul, das zonas rurais para os centros urbanos destes estados. A grande maioria era de ex-escravos ou trabalhadores sem formação que visualizavam oportunidades nas cidades mais próximas ${ }^{14}$. A chamada Grande Migração, por sua vez, iniciada no ano de 1915, teve um alcance muito mais amplo e grande impacto econômico e social nas cidades que receberam esta população. Essa corrente migratória envolvia desde mão de obra sem qualificação até profissionais graduados que não encontravam mercado em suas cidades.

\section{Chicago Defender e o sonho das Metrópoles Negras}

A ascensão do jornal Chicago Defender, enquanto um periódico de distribuição nacional, está associada intimamente à Grande Migração. Como observamos anteriormente, a publicação surgiu como um humilde empreendimento de estrutura precária, se profissionalizou, aumentando o seu número de leitores durante a década de 1910. O sucesso do Defender deveu-se, em parte, à formação de comunidades negras nos grandes centros urbanos dos Estados Unidos, principalmente o cinturão negro no South Side de Chicago. Esta cidade, que no passado contava com pequena quantidade de negros livres (conhecidos como pioneiros) ${ }^{15}$, tornou-se destino favorito dos migrantes, que vislumbravam possibilidades de emprego, estimulados por ideias e representações das grandes metrópoles negras.

Sendo assim, se por um lado o Chicago Defender foi impulsionado pela Grande Migração, por outro se transformou em órgão fundamental para difusão de uma "Terra Prometida" para os trabalhadores negro do sul. O periódico, contudo, não foi a influência única na tomada de decisão dos migrantes. Outros fatores contribuíram para o fluxo migratório, como a violência racial nos Estados Unidos, a situação econômica pelo a qual passava o país, além da expectativa de entrada dos Estados Unidos na Primeira Guerra Mundial, que acelerou a indústria norte-americana e deu início ao recrutamento de muitos homens com ocupações no mercado de trabalho nos grandes centros. O conflito no continente europeu também comprometeu a corrente imigratória de europeus para os Estados Unidos, oferecendo a oportunidade não somente para os homens negros, mas

14 GREGORY, James N. The southern diáspora: how the great migrations of black and white southerners transformed America. Chapel Hill: North Carolina University Press, 2005.

15 Ver REED, Christopher Robert. Black Chicago's First Century, 1833-1900. Columbia; London: University of Missouri Press, 2005. 
também para mulheres que estavam igualmente afastadas das indústrias. Com uma perspectiva negativa em relação ao fornecimento de mão de obra, a própria indústria desafiou o preconceito e atraiu um grupo específico de trabalhadores que sequer ocupava espaço nos sindicatos norteamericanos. Portanto, diante desse quadro que favorecia o deslocamento do sul em direção às cidades do norte, o Chicago Defender se tornou um importante agente neste processo que envolveu cerca de 3,5 milhões de pessoas entre anos de 1915 e $1930^{16}$.

Chicago tem a reputação de ser grande e ampla, e de fato é em muitas coisas. Nosso grupo racial trata essa cidade como um Oasis nesse tão falado "país democrático". ${ }^{17}$

Além do periódico de Robert Abbott, outros jornais da imprensa negra também trataram dos problemas nos estados sulistas e difundiram as representações de uma vida negra moderna em cidades como Detroit, Nova Iorque e Filadélfia. O Afro-American Baltimore e o Pittsburgh Courier competiam com o Defender, constituindo redes de distribuição de alcance nacional, que transformaram publicações rudimentares em redações profisssionais que lançavam mão de técnicas inovadoras de diagramação, publicidade e estratégias diversas para atrair assinantes ${ }^{18}$. Porém, tais periódicos estiveram longe de atingir sucesso semelhante ao do Chicago Defender durante o seu auge entre os anos de 1915 e 1940.

Robert Abbott foi o pioneiro do jornalismo profissional entre a imprensa negra, demonstrando habilidade como empreendedor ao utilizar funcionários dos vagões de trem como agentes de distribuição pelo território norte-americano. O principal objetivo do redator afroamericano era o de atingir um potencial publico leitor no sul do país. A grande maioria desses trabalhadores que serviam os viajantes era negra, o que facilitava a propaganda boca a boca no início da circulação do Defender pelas comunidades negras do sul ${ }^{19}$. Abbott identificou uma oportunidade para o seu jornal ao perceber a dificuldade dos periódicos da imprensa negra do sul em se estabelecerem em meio à precariedade de recursos e ao empastelamento de suas redações por parte dos racistas. Além disso, já havia certa demanda por parte dos leitores por notícias específicas sobre as condições das populações negras do norte, privilegiando o Chicago Defender enquanto o órgão para divulgação dessas informações.

16 GREGORY, James N. The southern diáspora: how the great migrations of black and white southerners transformed America. Chapel Hill: North Carolina University Press, 2005, p. 13.

17 “Duty of public utility”. Chicago Defender (Chicago, 12 de abril de 1919). p.24.

18 Idem, Ibidem, p. 50.

19 BATES, Beth Tompkins. The unfinished task of emancipation: protest politics come of age in Black Chicago, 19251933. Tese de Doutorado, Columbia University, 1997. (mimeogr.), 148-149. 
Concomitantemente aos primeiros passos dados para a circulação do jornal em escala nacional, Robert Abbott adequou a linguagem do periódico aos novos leitores, explorando as imagens violentas do sul e as da modernidade negra de Chicago. Como observamos anteriormente, Abbott e seu editor utilizaram propositadamente uma abordagem sensacionalista o que implicava, principalmente, na publicação de imagens de linchamentos e de pessoas violentadas. A estratégia comercial deu certo, contudo instigou vários ativistas negros que questionaram o valor político do jornal $^{20}$. O editor ganhou a fama de oportunista que, em certos momentos, prevaleceu sobre a sua condição de voz importante contra o racismo norte-americano.

O certo é que com a reconfiguração do Chicago Defender, Robert Abbott estreitou os laços com um amplo grupo de leitores nos Estados Unidos. Além das cartas enviadas dos migrantes de Chicago para o seus familiares no Sul, e das palavras persuasivas de agentes de empregos de indústrias no norte, os negros de diversas cidades sulistas passaram a contar com o periódico negro como meio fundamental para acessar as informações sobre o universo afro-americano daquele período. Abbott não somente informava o seu leitor sobre as "maravilhas" de Chicago e Nova Iorque, mas também oferecia um panorama das experiências negras por todo o país, reforçando o caráter nacional do Defender.

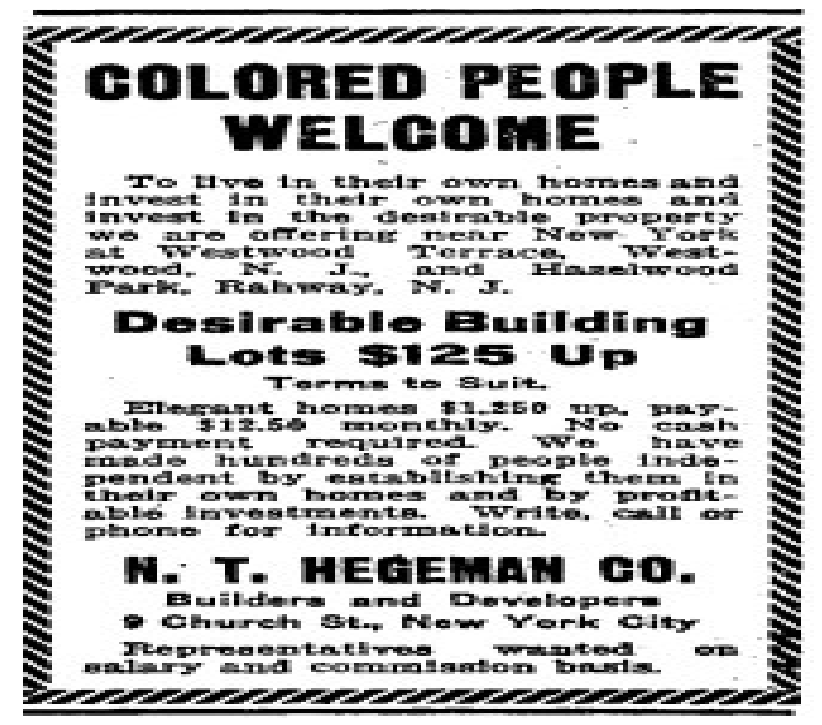

Figura 0: Anúncio de imóveis que dava boas vindas aos migrantes negros de Nova lorque. Chicago Defender de 12 de fevereiro de 1919.

Para marcar a presença de seu jornal no Sul, o editor, até mesmo, recompensou financeiramente artistas e pregadores que promoviam o Chicago Defender entre suas audiências. O

20 Para conflito de Abbott com outros ativistas ver DESANTIS, Alan D. “A forgotten leader Robert S. Abott and the Chicago Defender from 1910-1920”. In: Journalism History, v. 23, p. 63-71. 
periódico se tornou um elemento presente em diversas cidades, sendo distribuído em pontos estratégicos de circulação como barbearias e igrejas. De modo a valorizar o Defender, seus editores afirmavam que o cálculo do número de leitores não deveria levar em consideração somente os números oficiais da tiragem, já que um mesmo exemplar poderia passar pelas mãos de pelo menos cinco pessoas.

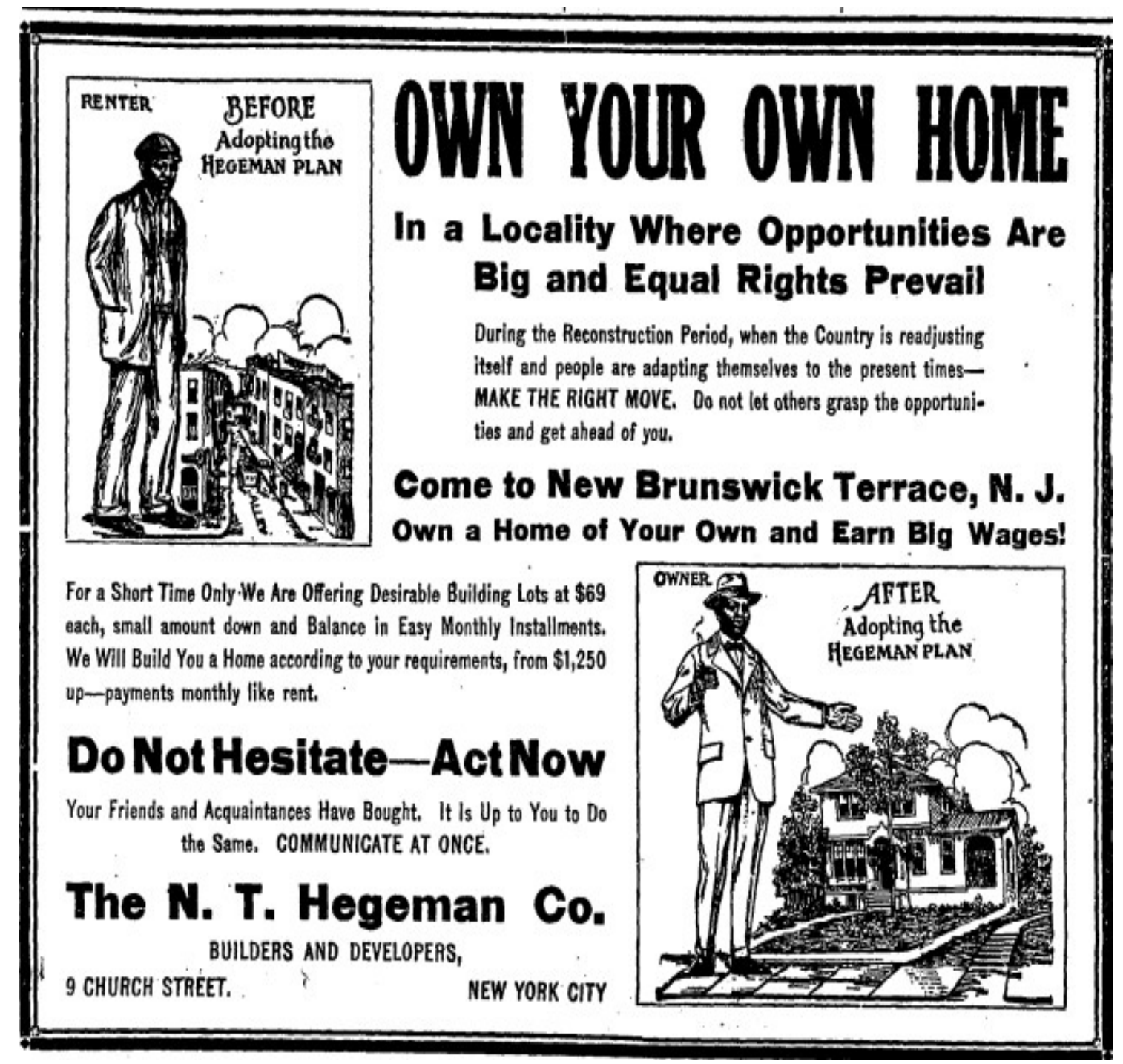

Figura 0: Anúncio de imóveis de Nova Jérsei, apresentada como uma cidade de “igualdade de oportunidades". Chicago Defender de 5 março de 1919.

Um expediente muito vantajoso para fazer a divulgação de Chicago foi a propaganda de produtos domésticos, de beleza e de casas de shows. Desta forma, o Defender fazia circular imagens 
positivas da cidade e ainda lucrava com os anúncios publicitários. A possibilidade de participação na modernidade norte-americana se cristalizava, em parte, a partir do consumo de eletrodomésticos e mobílias. Com a informação de que as próprias lojas ofereciam crédito para a aquisição dos produtos, o Defender pintava um quadro favorável, construindo uma realidade sem obstáculos financeiros na qual os migrantes viam-se incorporados ao universo do trabalho e do consumo. $\mathrm{O}$ jornal, por exemplo, anunciava itens básicos para a cozinha e aparelhos mais caros como refrigeradores que, reunidos em um conjunto, criavam a representação do negro moderno assimilado pela sociedade norte-americana. Entre os produtos, a sensação era o fonógrafo, que no jornal aparecia como referência fundamental de sofisticação que estaria disponível somente para a população negra dos grandes centros do norte dos Estados Unidos ${ }^{21}$.

Roupas e produtos de beleza não poderiam ficar de fora: ternos, vestidos e casacos de peles dominavam as propagandas do Chicago Defender. Ainda que parte dos modelos fosse branca, estimulavam a imaginação dos leitores negros do jornal, transformando a cidade de Chicago na capital da moda afro-americana. Já os cosméticos se destacavam com os registros de maiores lucros entre os consumidores negros, principalmente as mulheres. Entre os produtos com as maiores demandas estavam os cremes para alisar os cabelos e os clareadores de pele. Nas imagens sobre os alisadores, observarmos mulheres sorrindo e atestando a qualidade do produto ao passar a mão pelo próprio cabelo de maneira suave. É curioso notarmos que o periódico tinha como objetivo lutar contra o racismo, divulgando imagens de uma prosperidade negra nas cidades do norte, ao mesmo tempo em que anunciava produtos para aproximar uma pessoa de pele escura do padrão branco. Ainda que o Chicago Defender se esforçasse para definir uma experiência negra para a modernidade norte-americana, a referência de uma beleza branca tinha impacto significativo sobre os afro-americanos, gerando a convivência entre discursos de dignidade negra com os processos de branqueamento dos negros dos Estados Unidos.

21 DESANTIS, op. cit., 1993, p. 186. 


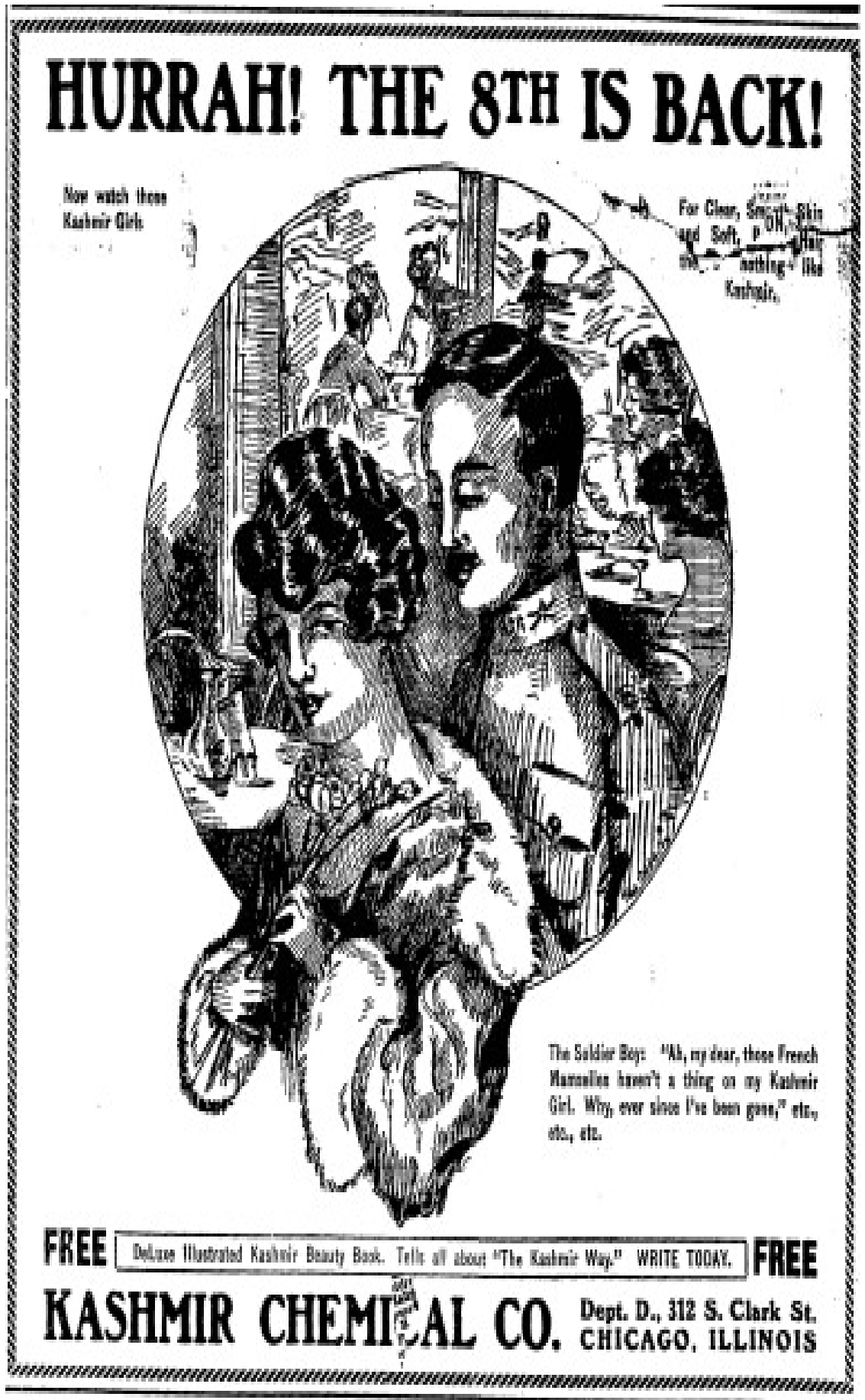

Figura 0: Publicidade de roupas. Chicago Defender de 22 de fevereiro de 1919.

Outro tema explorado pelo Chicago Defender para ilustrar as vantagens da vida na cidade foi o do lazer. Se nas cidades do sul as possibilidades para um momento de descontração e diversão, sobretudo em um contexto social segregado, estavam limitadas, em Chicago os migrantes poderiam gozar de uma enorme variedade de eventos. As alternativas de entretenimento variavam entre concertos musicais, exibição de filmes, teatro, eventos esportivos e banhos no Lago Michigan. O periódico, que possuía uma seção dedicada ao assunto, informava os seus leitores sobre os eventos 
que ocorriam na cidade ${ }^{22}$. Entre os destaques, estavam os filmes com atuações de atores "da raça", principalmente aqueles com o elenco predominantemente negro ${ }^{23}$. Empenhado em retratar Chicago como uma cidade livre do racismo, o Defender se preocupou sempre em ressaltar como os negros eram aceitos em diferentes ambientes e não passavam por situações embaraçosas comuns em espaços segregados. Em um anúncio do clube de dança Chateau, o jornal demonstrou como um migrante, ou apenas um visitante do sul, poderia passar uma noite com os melhores músicos da cidade, num salão com muito brilho e com pessoas de diferentes "raças" dançando por quase três horas. A noite ainda poderia se encerrar no Hotel Pullman, com quartos de primeira classe ${ }^{24}$.

Entre as atividades de entretenimento com maior apelo estavam as modalidades esportivas, com especial destaque para o baseball. As principais ligas norte-americanas não permitiam a entrada de jogadores negros, por isso, indiretamente, estimularam a criação de equipes e ligas especificamente negras. Essa modalidade atraiu inúmeros admiradores e o Chicago Defender logo a utilizou como mais um elemento para ilustrar o fascinante ambiente da cidade. Em parte, a publicação ajudou o baseball das ligas negras ao divulgar jogos e transformar os atletas em estrelas. Um dos principais promotores do esporte era muito próximo de Robert Abbott, e o jornalista esteve indiretamente relacionado com a organização das equipes e dos torneios envolvendo atletas negros. Assim que o baseball começou a se estruturar, sobretudo a partir do sucesso do Chicago Giants, o Chicago Defender explorou o esporte e fez das coberturas verdadeiros espetáculos. Fotografias dos Giants foram publicadas diversas vezes e os atletas eram representados não somente como referências de uma modalidade, mas também como símbolos do progresso da população negra em Chicago e em outras cidades do norte do país.

22 GROSSMAN, op. cit., p. 86.

23 DESANTIS, op. cit., 1993, p. 193

24 Idem, Ibidem, p. 196. 


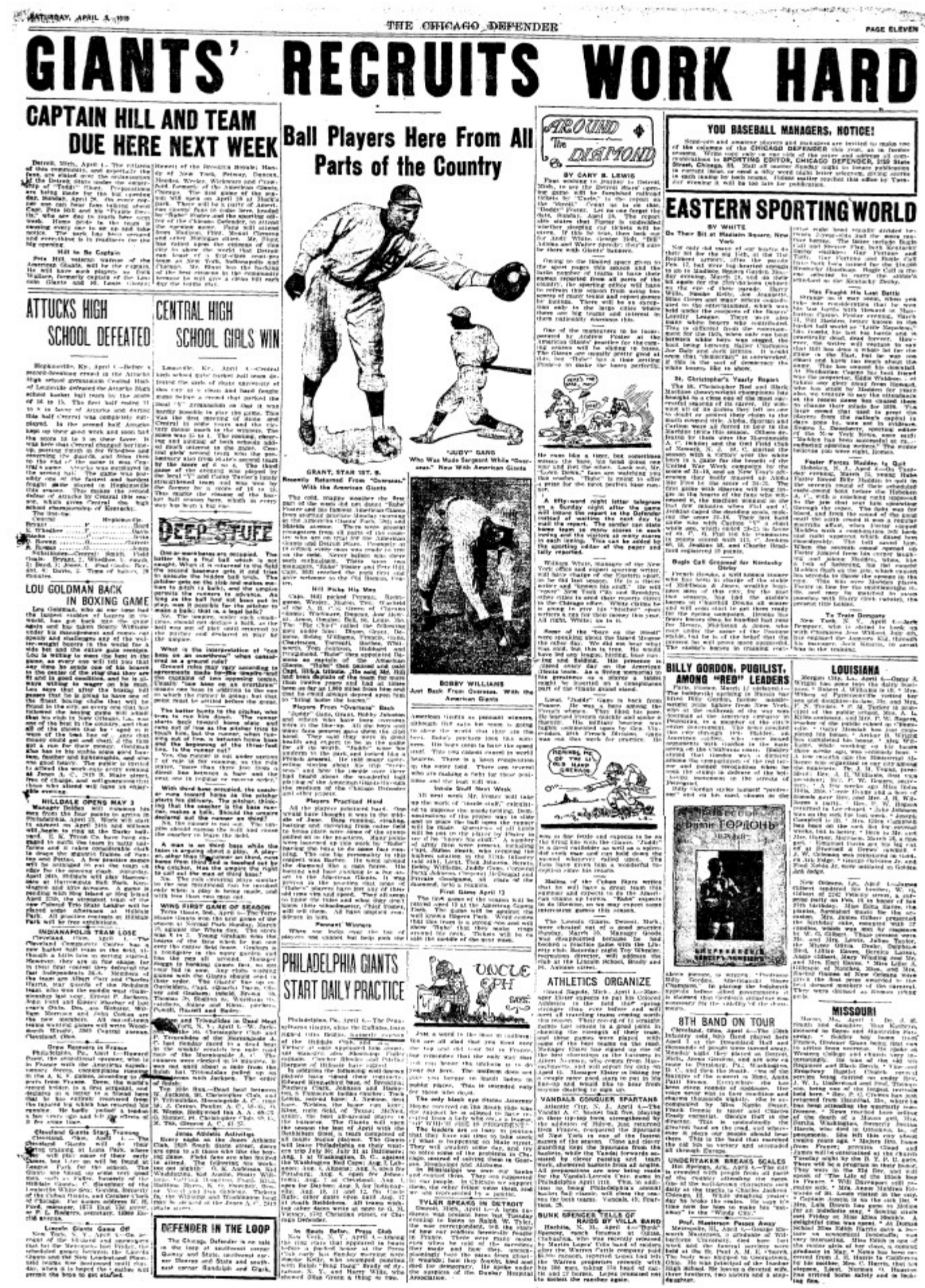

Reproduced with permission of the copyright owner. Further reproduction prohibited without permission.

Figura 0: Páginas de esportes com imagens de jogadores de baseball. Chicago Defender de 5 de abril de 1919.

O sucesso do próprio periódico também poderia ser considerado como resultado da 
prosperidade afro-americana em Chicago. Robert Abbott, que havia chegado à cidade com poucos recursos financeiros, tornou-se um dos negros mais ricos de Chicago e representante de um seleto grupo de empreendedores afro-americanos que lucravam com serviços e produtos oferecidos especificamente para a população negra. Assim como muitos migrantes que chegavam à cidade, Abbott deixou um estado do sul, a Geórgia, buscando oportunidades ao norte. Ainda que, diferentemente da perspectiva do Chicago Defender e outros jornais negros do período, cientistas sociais apontassem os limites das cidades do norte ${ }^{25}$, demonstrando como o racismo se manifestava em diferentes espaços, é inegável que as possibilidades de organização de entidades políticas e empreendimentos econômicos eram maiores. Madam C. Walker, empresária do ramo de cosméticos, estabeleceu a cidade de Chicago como o centro de articulação de sua rede de distribuição de produtos de beleza. Walker foi a primeira afro-americana a atingir um patrimônio de um milhão de dólares, seu negócio empregou cerca de vinte mil mulheres, oferecendo alternativas aos empregos domésticos ${ }^{26}$. Os exemplos de prosperidade, ainda que raros, não eram uma total fantasia, estavam presentes e legitimavam o discurso de apoio à migração dos afro-americanos.

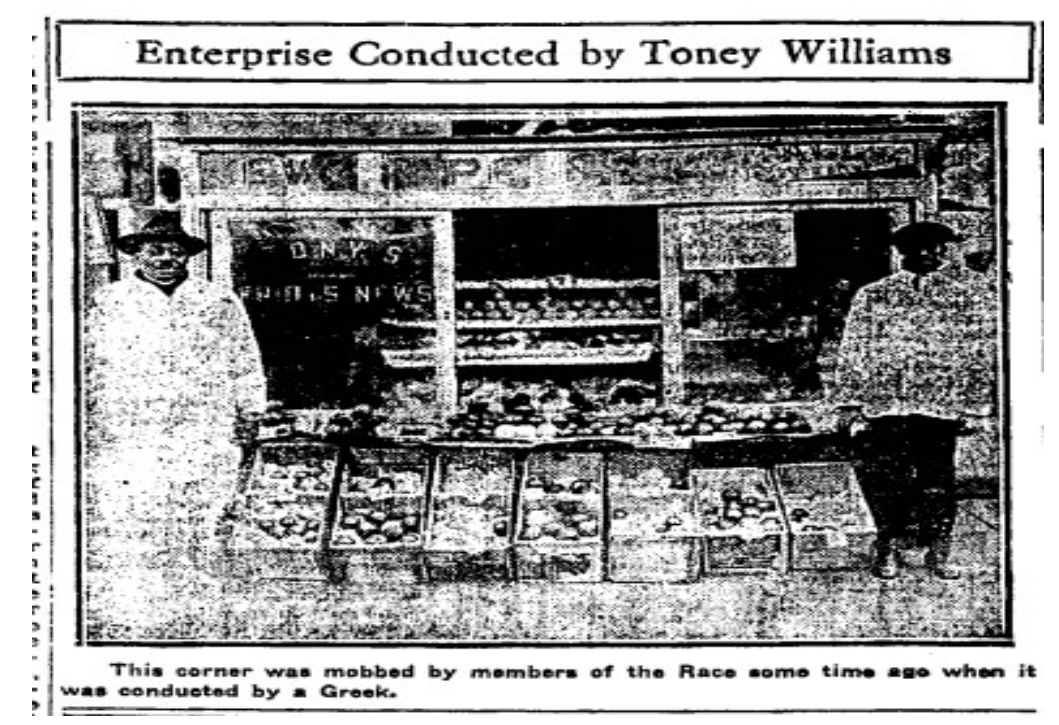

Figura 0: Fotografia de negócio administrado por um negro em Chicago. Chicago Defender de 22 de fevereiro de 1919.

Nesse sentido, Robert Abbott promoveu sua própria imagem e de outros empresários negros, a maioria deles com uma trajetória profissional que se adequava às narrativas de self-made man. A campanha em prol da Grande Migração no jornal Chicago Defender revelou uma versão afro-americana do Sonho Americano. Ao longo da História, esse mito se baseou em valores como a

25 Ver DRAKE, St. Clair; CAYTON, Horace R. Black Metropolis: A study of Negro life in northern city. New York: Harper, 1962.

26 BALDWIN, Davarian L. Chicago's Negroes: modernity, Great Migration and Black urban life. Chapel Hill: University of North Carolina Press, 2007. 
ética do trabalho e aquisição de riqueza. Com a ascensão da indústria e, consequentemente, de classes sociais capazes de consumirem os seus produtos, o próprio consumo passou a compor o Sonho Americano nas primeiras décadas do século $\mathrm{XX}^{27}$. Robert Abbott mobilizou uma série de imagens da prosperidade negra, estimulando o "apetite" de segmentos da população negra por consumo através da linguagem dos anúncios comerciais.

A ideia de novo negro, contudo, foi além do entretenimento e do empreendedorismo, ela se manifestou também por meio de condutas e códigos estéticos, recriando um negro urbano e moderno em oposição a uma representação rural associada ao espaço "retrógado" do sul dos Estados Unidos. O propósito do Chicago Defender era o de combater os estereótipos que circulavam entre os norte-americanos de inferioridade da população negra, construídos durante o período de escravidão. O novo negro que surge nas páginas do periódico seguia uma perspectiva elitista de Robert Abbott, que condenava inúmeros hábitos dos populares. Para o editor do Chicago Defender, os migrantes deveriam passar por um processo de educação moral capaz de transformálos em trabalhadores preparados para a modernidade norte-americana. Segundo ele, para evitar comentários racistas, era necessário que os migrantes dominassem um código de condutas para "manter a saúde, a sobriedade e a moralidade, evitando que todos os negros, inclusive os respeitáveis, caíssem em descrédito". Robert Abbott, então, elaborou uma lista do que não deveria ser feito:

Não utilizar linguagem vulgar em espaço público;

Não se envolver em brigas;

Não usar a liberdade para fazer qualquer coisa que quiser;

Não se juntar a pessoas que cometem delitos, sejam elas homens, mulheres ou crianças;

Não seja um estorvo público;

Não se aglomere nas ruas, atrapalhando os transeuntes;

Não gaste seu tempo em bares e salões de jogos;

Não more em casa insalubres ou durma em quartos sem ventilação;

Não abuse ou viole a confiança daqueles que oferecem emprego;

Não deixe o emprego depois de ganhar alguns dólares;

Não trabalhe por um salário menor enquanto outros trabalhadores desempenham a mesma atividade por uma quantia maior;

Não permita que crianças menores de 15 anos circulem pelas ruas depois das 21 horas;

Não beba e saia pelas ruas insultando mulheres e crianças como se fosse

27 DESANTIS, op. cit., 1993, p. 67. 
uma besta. ${ }^{28}$

Ao seu modo, o Chicago Defender lutou pela integração dos afro-americanos, mas sem confrontar completamente a ordem social norte-americana. O jornal se empenhou em incluir a população negra em uma comunidade política, mas sem refletir profundamente sobre as consequências de um racismo que transcendia o universo das instituições e se reproduzia na cultura. O novo negro de Abbott tinha um caráter assimilacionista, mobilizando símbolos e representações usualmente utilizados por grupos da elite branca do país para legitimar uma condição privilegiada. Porém, as páginas do periódico revelam apenas uma das várias subjetividades negras naquele período. Se no Chicago Defender encontramos uma resposta moderada para as transformações sociais em curso nas primeiras décadas do século XX, no discurso de outras lideranças, como Hubert Harrison, William Dubois e Marcus Garvey, já é possível identificarmos uma crítica ao capitalismo e ao imperialismo permeados pelo socialismo radical negro e o pan-africanismo.

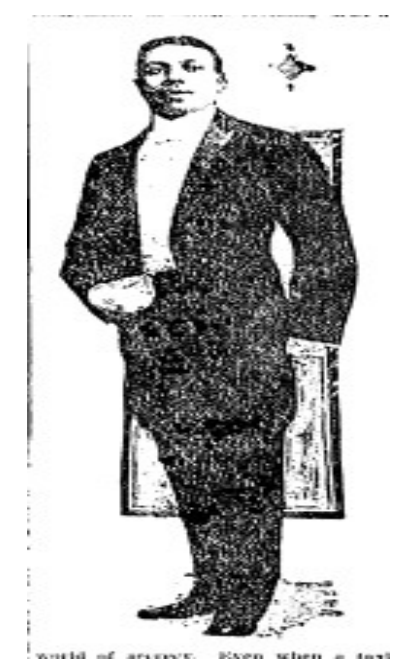

Figura 7: Imagem do ator Tom Brown. Chicago Defender de maio de 1919.

Uma solução similar ao do Chicago Defender se apresentou no ativismo negro de outros países. Algumas lideranças negras brasileiras e cubanas, nesse mesmo período, também criaram representações de um novo negro a partir da noção de respeitabilidade, reforçando a preocupação em guiar uma população negra ainda não “habituada” à experiência de liberdade em uma ordem capitalista. Nos clubes sociais das “elites negras” de São Paulo e Havana, o ativismo que emergia nas primeiras décadas do século XX debatia o lugar das populações negras nos projetos nacionais, assumindo agendas assimilacionistas com discursos de um negro moderno despido de elementos da

28 “Some don’ts”. Chicago Defender (Chicago, 17 de maio de 1919), p.20. 
cultura popular negra, tratados como sinais de atraso e barreiras para o progresso social. ${ }^{29}$ Expressões culturais e religiosas associadas à africanidade foram eliminadas para a concepção de um novo negro ajustado às necessidades de uma nova era. O discurso do Chicago Defender e dessas lideranças negras na América Latina criaram narrativas de uma redenção negra em um período pósabolição a partir de termos como elevação moral, racial uplift e respetabilidad.

O repertório de representações positivas sobre as metrópoles negras nas páginas do jornal ainda contava com o argumento da participação política. Como observamos anteriormente, os afroamericanos perderam o direito de voto em vários estados do sul dos Estados Unidos. O estado de Illinois, onde estava situada Chicago, após anos de restrições no século XIX, assegurou o direito ao voto. O Chicago Defender participou ativamente nas eleições, principalmente nas municipais, procurando influenciar de maneira deliberada o voto dos seus leitores. O periódico sempre manifestou a sua posição a favor do Partido Republicano, nunca esquecendo o papel deste na abolição da escravidão, reforçando sua aura associada ao presidente Abraham Lincoln. Já no início do século XX, cidadãos negros de Chicago se juntavam às redes clientelistas da cidade que consolidavam, cada vez mais, a suas máquinas eleitorais. Uma das maiores da história da cidade foi construída justamente com o apoio maciço do eleitorado negro. A era do prefeito William Thompson, com quatro administrações entre 1915 e 1931, mobilizou os negros e alguns grupos de imigrantes, como os italianos. ${ }^{30}$ Em abril de 1919, o Chicago Defender celebrava a vitória de Thompson, observando que havia sido o único jornal da cidade que o apoiara durante as eleições e que a zona onde se concentrava a população negra havia sido decisiva.

Essa é uma vitória não somente para Thompson, mas para o Chicago Defender também. Esta afirmação é evidenciada por uma manchete com título em negrito na edição de quarta que dizia: "NEGROS VOTEM EM BIG BILL", enquanto todos os outros jornais dolorosamente admitem que foi o voto de nosso grupo de pessoas que aniquilou as forças combinadas da oposição. A modéstia nos impede de alegar que "o Maior Semanário do Mundo" tem mais influência política do que todos outros jornais diários

29 Ver GURIDY, Frank Andre. Forging diáspora: Afro-Cubans and African-Americans: in a world of empire and Jim Crow. Chapel Hill: University of North Carolina Press, 2010; DE LA FUENTE, Alejandro. A Nation for all: race, inequality, and politics in Twentieth Century Cuba. Chapel Hill: The University of Carolina Press, 2001; BUTLER, Kim D. Freedoms given, freedoms won: Afro-Brazilian in post- abolition, São Paulo and Salvador. New Brunswick: Rutgers University Press, 1998; DOMINGUES, Petrônio. Uma história não contada: negro, racismo e branqueamento no São Paulo pós-abolição. São Paulo: Senac, 2004

30 Ver BATES, Beth Tompkins. The unfinished task of emancipation: protest politics come of age in Black Chicago, 1925-1933. Tese de Doutorado, Columbia University, 1997. (mimeogr.) e GUGLIEMO Thomas A. Whites on Arrival: Italians, race, color, and Power in Chicago, 1890-1945. New York: Oxford University Press, 2004. 
combinados, mas sãos os resultados que contam. ${ }^{31}$

No excerto podemos identificar a intenção do periódico em se colocar como um representante da comunidade negra de Chicago e se afirmar como uma força política que estaria por trás do sucesso de William Thompson nas eleições municipais de 1919, influindo decisivamente nas eleições. Nesse sentido, o Chicago Defender demonstrava aos leitores que a possibilidade de inserção no mercado de trabalho era acompanhada de uma participação política capaz de influenciar as eleições locais. A máquina eleitoral do Big Bill (como era conhecido popularmente o prefeito) se baseou na indicação de políticos negros a cargos públicos e teve pouca força para contrabalancear os esforços para a segregação dos negros em Chicago, já que a rede clientelista dependia de outros grupos imigrantes. No entanto, o Chicago Defender não deixou de capitalizar as "vitórias" para reforçar a sua agenda política.

31 "Second ward vote decided the political battle; Sweitzer is smothered, Hoyne forgotten". Chicago Defender (Chicago, 5 abril de 1919), p.1. 


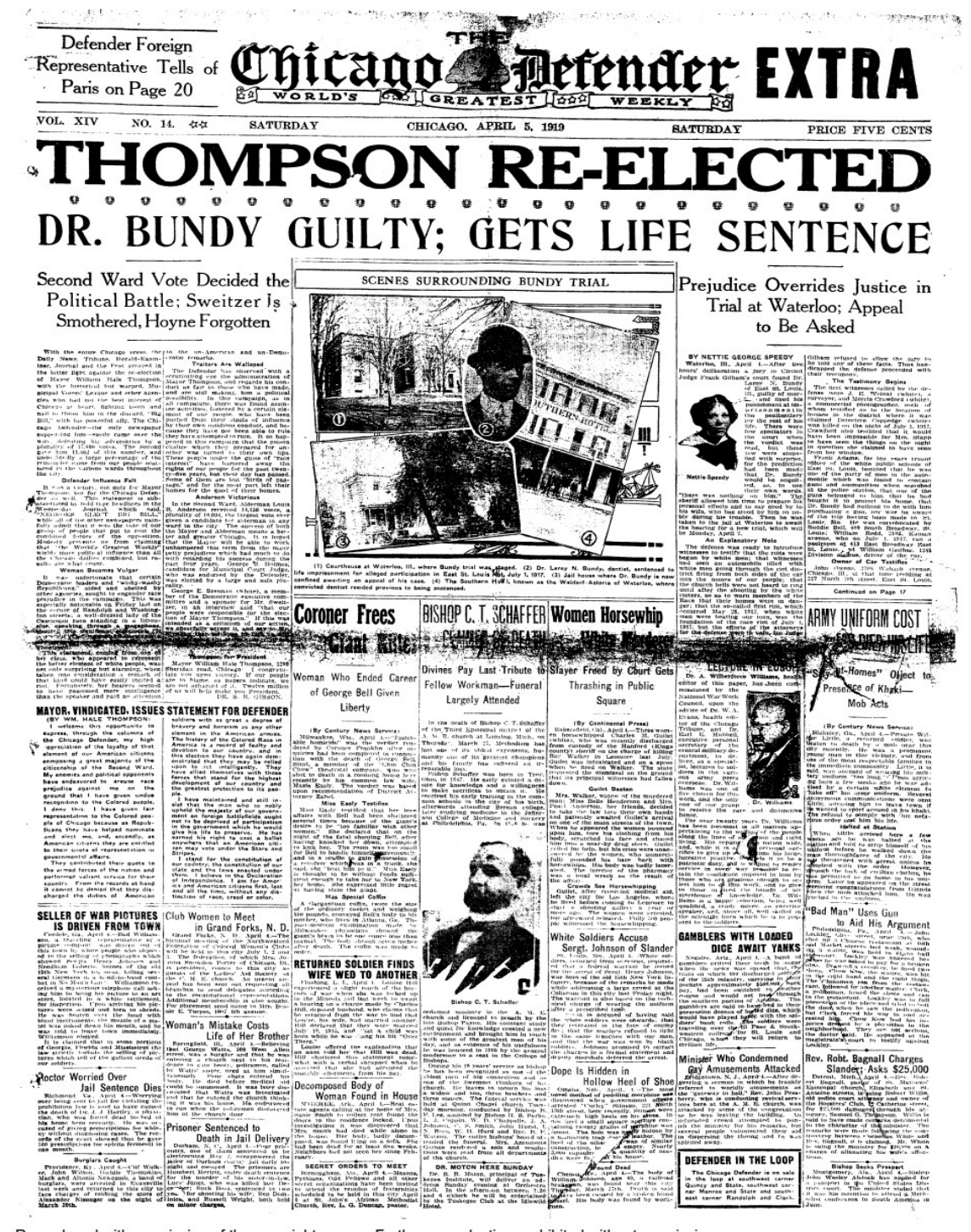

Figura 8: Primeira página com o anúncio de reeleição de William Thompson.

Para além do discurso sobre o novo negro nas metrópoles norte-americanas do Chicago Defender, havia uma grande expectativa em torno da Primeira Guerra Mundial. O conflito na Europa, com a possibilidade de participação de soldados negros combatendo pelos Estados Unidos, foi considerado um evento crucial para vida política da população negra no país. Alguns ativistas negros por meio dos periódicos procuraram explorar o acontecimento, argumentando que a cooperação dos afro-americanos na guerra deveria ser acompanhada por um esforço político do presidente Woodrow Wilson de confrontar a violência racial, já que o mesmo havia afirmado que o país promoveria a democracia no continente europeu. Portanto, o suor dos combatentes negros deveria ser retribuído com a promoção da igualdade racial em todo o território norte-americano: 
Democracia significa o povo, o espírito e o propósito do povo; significa a guerra do povo; significa que o povo terá a benção da liberdade, do autogoverno e do usufruto dos direitos inalienáveis da vida, da liberdade e propriedade. Os Estados Unidos não estão satisfeitos em ter a democracia somente para si, o país deseja que todos os países no planeta tenham. A democracia não estará satisfeita até que todos os homens estiverem sobre sua influência benévola.

O preconceito racial, particularmente aquele contra o negro, é uma daquelas nuvens que tampam o sol, os Estados Unidos devem também superar isso, a democracia deve remover essas nuvens. O negro é parte do povo, ele é um nativo dos Estados Unido e não conhece outro país. O negro têm doado o seu sangue pelo país, não há razões para a rude, insensível e brutal discriminação praticada nessa terra democrática contra ele $[\ldots]^{32}$

A euforia em torno da Primeira Guerra Mundial, entretanto, não duraria muito tempo. $\mathrm{O}$ retorno dos soldados foi acompanhado por tensão, que culminaria em uma série de conflitos raciais no país. Se por um lado os negros reivindicavam uma cidadania de primeira classe, por outro forças políticas se empenhavam em preservar a ordem social anterior ao conflito na Europa, reforçando ainda mais as hierarquias raciais. Em 1919, cidade de Chicago, idealizada pelo Chicago Defender, se transformaria em um dos palcos desta onda de violência. Após o afogamento de um garoto negro no Lago Michigan, causado por um banhista branco que o havia atingido com uma pedra para impedi-lo de se aproximar de uma área predominantemente branca, negros e brancos se digladiaram nas ruas da cidade, gerando caos por alguns dias. ${ }^{33}$

32 “America”. Chicago Defender (Chicago, 9 de setembro de 1918), p. 16.

33 Ver TUTTLE, William M. Race riot: Chicago in the Summer of 1919. Champaign: University of Illinois Press, 1996. 
BRAVE DEEDS OF "BLACK DEVILS" TOLD

The Chicago Defender (Big Weekend Edition) (1905-1966); Feb 22, 1919;

ProQuest Historical Newspapers: Chicago Defender (1910-1975)

\section{BRAVE DEEDS OF “BLACK DEVILS" TOLD

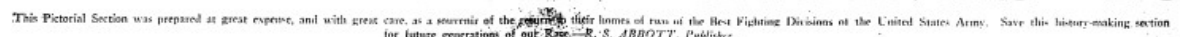

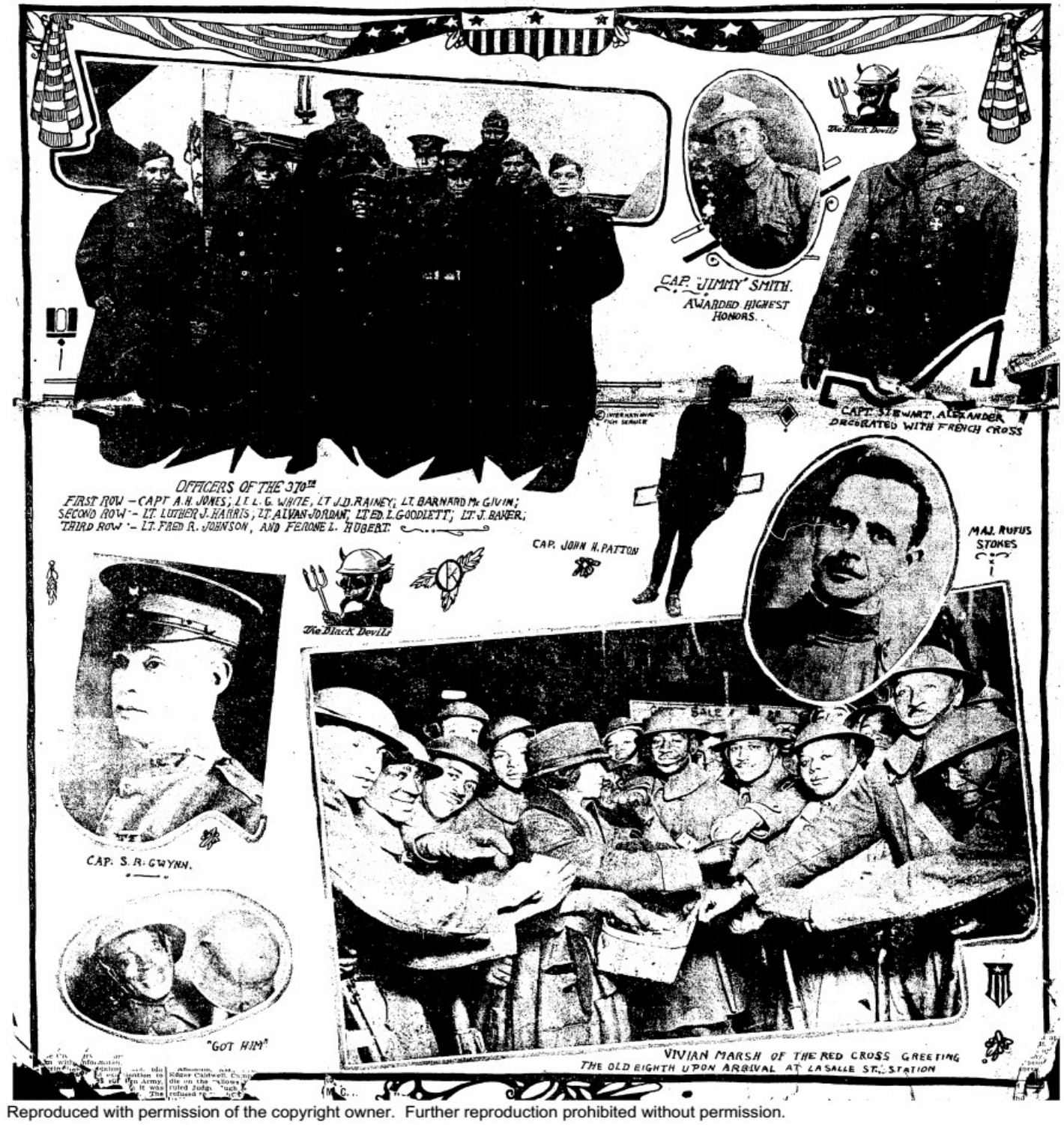

Figura 9: O Chicago Defender celebra os militares negros. Chicago Defender de 22 de fevereiro de 1919.

O tumulto em Chicago comprometeu o discurso do periódico negro que atribuía à cidade características de uma "metrópole negra". O editor Robert Abbott reconheceu que as relações raciais nas cidades do norte haviam se transformado, devido ao acirramento das tensões entre negros e brancos. Ele, contudo, acreditava que o problema racial não tinha necessariamente suas raízes nas relações sociais nortistas. Atribuía as tensões ao movimento de "conscientização" dos negros norte-americanos e simultaneamente à influência sulista. $\mathrm{O}$ editor passou a reconhecer que a Grande Migração não havia sido um fenômeno exclusivamente negro, uma vez que a arrebatadora 
depressão econômica dos primeiros anos do século XX levou muitos migrantes brancos pobres às metrópoles do norte, trazendo também o racismo "típico do sul”, que teria sido responsável pelos tumultos do verão de 1919:

Isso não é estranho, portanto, que ideias do sul que fazem referência ao nosso grupo sejam difundidas por todo o Norte. Eles espalham o veneno que intensifica o ódio racial. O filme chamado "O nascimento de uma nação" vem completando o trabalho deles para realização desse propósito. Esses tumultos, nesse sentido, não são mais do que o transplante dos métodos sulistas em solo nortista. A despeito do efeito que a exibição desse filme possa provocar, não se verifica a sua influência sobre o homem do norte. $\mathrm{O}$ sulista que hoje mora no Norte e se mascara de nortista é o único responsável pelos distúrbios. ${ }^{34}$

Ainda que Robert Abbott afirmasse a existência de uma cultura cosmopolita no norte dos Estados Unidos, atribuindo aos brancos do sul as práticas racistas, estava claro para ele que toda a sociedade norte-americana havia passado por mudanças, e que a cidade de Chicago após o verão de 1919 não poderia ser retratada como um refúgio livre de racismo, como ele próprio fizera anteriormente nas páginas do Chicago Defender. A Primeira Guerra Mundial foi encarada pelos negros como o reconhecimento definitivo dos serviços prestados por eles à nação. Os soldados que estiveram no fronte não eram apenas combatentes com característica fenotípicas singulares, mas homens que simbolizavam milhões de afro-americanos. Além disso, compreendiam que sua participação no conflito poderia contribuir para elevar os Estados Unidos à posição de potência mundial. O cálculo de que a guerra poderia abrir o caminho para os negros na sociedade ignorou a dimensão do racismo no país, que fazia-se presente em todo o território nacional e principalmente, segundo os ativistas do período, nas instituições federais. ${ }^{35}$

O crítico literário Henry Louis Gates afirma que a ideia de "novo negro" foi recorrente na produção intelectual afro-americana até a década de 1920, apresentando como um conjunto de representações positivas sobre a população negra, com o objetivo de confrontar as representações do negro que circulavam até então na literatura e meios de comunicação. ${ }^{36} \mathrm{O}$ novo negro que emerge nas páginas do Chicago Defender foi uma resposta às mudanças sociais e econômicas nas

34 “Masqueraders". Chicago Defender (Chicago, 30 de agosto), página do editorial.

35 Para entender a segregação institucional nos Estados Unidos ver KING, Desmond. Separate and Unequal: Black Americans and the US Federal Government. New York: Oxford University Press, 1995.

36 GATES Jr., Henry Louis. "The trope of a New Negro and the Reconstruction of the image of the Black". In: Representations, n.24, Special Issue: America Reconstructed, 1840-1940 (outono, 1988), pp. 129-155. 
primeiras décadas do século XIX. Algumas lideranças afro-americanas, entre elas Robert Abbott, compreenderam esse contexto como um processo de modernização da população negra. Neste sentido, a Grande Migração foi apresentada como uma espécie de narrativa de redenção do negro na sociedade norte-americana, que deixaria para trás o legado escravista, ascendendo, através da modernidade, a uma nova ordem social, livre dos estigmas e práticas racistas.

\section{REFERÊNCIAS}

BALDWIN, Davarian L. Chicago's Negroes: modernity, Great Migration and Black urban life. Chapel Hill: University of North Carolina Press, 2007

BATES, Beth Tompkins. The unfinished task of emancipation: protest politics come of age in Black Chicago, 1925-1953. Tese de Doutorado, Columbia University, 1997. (mimeogr.).

BUTLER, Kim D. Freedoms given, freedoms won: Afro-Brazilian in post- abolition, São Paulo and Salvador. New Brunswick: Rutgers University Press, 1998;

DE LA FUENTE, Alejandro. A Nation for all: race, inequality, and politics in Twentieth Century Cuba. Chapel Hill: The University of Carolina Press, 2001.

DESANTIS, Alan D. Selling the American Dream: The Chicago Defender and Great Migration of 1915-1919. Tese de Doutorado, Universidade de Indiana, 1993. (mimeogr.)

DESANTIS, Alan D. "A forgotten leader Robert S. Abott and the Chicago Defender from 19101920”. In: Journalism History, v. 23, p. 63-71.

DRAKE, St. Clair; CAYTON, Horace R. Black Metropolis: A study of Negro life in northern city. New York: Harper, 1962.

DU BOIS, William E. B. As almas da gente negra. Rio de Janeiro: Lacerda Editores, 1999.

ELLIS, Charlesetta Maria. Robert S. Abbott's response for education for African-Americans via the Chicago Defender, 1909-1940. Tese de Doutorado, Universidade Loyola de Chicago, 1994. (mimeogr.)

FONER, Eric. Reconstructon: America's unfinished revolution (1863-1877). New York: Harper \& Row, 1988.

GATES Jr., Henry Louis. "The trope of a New Negro and the Reconstruction of the image of the Black”. In: Representations, n.24, Special Issue: America Reconstructed, 1840-1940 (outono, 1988), pp. 129-155

GREGORY, James N. The southern diáspora: how the great migrations of black and white southerners transformed America. Chapel Hill: North Carolina University Press, 2005.

GROSSMAN, James R. Land of Hope: Chicago, Black Southerners, and the Great Migration. University of Chicago Press, 1989.

GURIDY, Frank Andre. Forging diáspora: Afro-Cubans and African-Americans: in a world of empire and Jim Crow. Chapel Hill: University of North Carolina Press, 2010.

KING, Desmond. Separate and Unequal: Black Americans and the US Federal Government. New York: Oxford University Press, 1995. 
PRIDE, Armistead S. \& WILSON II, Clint C. A history of the black press. Washington, D.C.: Howard University Press, 1997.

REED, Christopher Robert. Black Chicago's First Century, 1833-1900. Columbia; London: University of Missouri Press, 2005.

RITTERHOUSE, Jennifer. Growing up Jim Crow: how black and white southern children learned race. Chapel Hill: The University of South Carolina Press, 2006.

SCOTT, Emmett J. "Letters of Negro Migrants of 1916-1918”. In: The Jornal of Negro History, Volume IV, n. 3, (Julho, 1919), p. 290-340.

TUTTLE, William M. Race riot: Chicago in the Summer of 1919. Champaign: University of Illinois Press, 1996. 